\title{
Induction Coil Heating Improves the Efficiency of Insect Olfactory Studies
}

\author{
Liu Yang ${ }^{1}$, Yuzhe Liu ${ }^{2}$, Gary M. Richoux ${ }^{1}$, Ulrich R. Bernier ${ }^{3}$, Kenneth J. Linthicum ${ }^{3}$ and \\ Jeffrey R. Bloomquist ${ }^{1 *}$ \\ ${ }^{1}$ Department of Entomology and Nematology, Emerging Pathogens Institute, University of Florida, Gainesville, FL, \\ United States, ${ }^{2}$ Department of Materials Engineering, Auburn University, Auburn, AL, United States, ${ }^{3}$ Center for Medical, \\ Agricultural and Veterinary Entomology, Agricultural Research Service, United States Department of Agriculture, Gainesville, \\ FL, United States
}

Electroantennography (EAG) is a commonly used method to study the olfactory responses of insects, but many behaviorally relevant odorant responses are difficult to evaluate because only a small amount of chemical sample is available in the vapor phase. We have assembled a coupled induction heating-electroantennogram (IH-EAG) system to improve the release efficiency of tested compounds. This system allows precise temperature control from room temperature to $600^{\circ} \mathrm{C}$ of the carbon steel wire without changing significantly the air delivery temperature to the antennae. After heating to $135^{\circ} \mathrm{C}$ (wire temperature read by a calibrated thermocouple), EAG response to $0.1 \mathrm{mg}$ of DEET increased from 0.11 to $0.33 \mathrm{mV}$, which is not significantly different from the EAG response to $1 \mathrm{mg}$ at room temperature (ca. $25^{\circ} \mathrm{C}$ ). Likewise, response to 1-octen-3-ol was detected at $0.1 \mathrm{mg}$ after heating to $135^{\circ} \mathrm{C}$ and was equivalent to $1 \mathrm{mg}$ at room temperature. For the low volatility compound VUAA-1, an experimental insect repellent, the $E A G$ response increased 60 -fold, from 0.16 to $9.52 \mathrm{mV}$ after heating to $500^{\circ} \mathrm{C}$ without degradation of the sample, as determined by NMR. Overall, this system can easily reduce the amount of chemical used in an EAG assay up to 10-fold and provided the compound is not thermally labile, allows for rapid testing of slow acting, less volatile compounds for eliciting an olfactory response from insects or other animals.

\section{Keywords: Aedes aegypti, DEET, electroantennogram, insect repellent, 1-octen-3-ol, vaporization, VUAA-1}

\section{INTRODUCTION}

Electroantennography (EAG) is a technique for measuring the difference in electrical potential across an insect antenna when exposed to a given odorant (Syntech, 2015), and has been commonly used in studies of chemical ecology and synthetic repellents. Although large EAG responses can be obtained from compounds such as insect pheromones, compounds only available in small amounts or those with low volatility result in small signals compared to background noise (Myrick and Baker, 2018). Increasing the amount of compound delivered to antennae is typically achieved by holding a treated filter paper within a sealed application pipette for up to $24 \mathrm{~h}$ to increase the vapor phase concentration (Stelinski et al., 2003), while a recent method employed a shortened pathway of the odor source to the antenna to prevent adsorptive loss and increased delivery efficiency (Ng et al., 2017).

Typically, EAG analysis is performed at room temperature, but field temperatures can easily fluctuate over 20 degrees during a diurnal cycle (Ma et al., 2015), which would be expected to change the blend of compounds having different volatilities in the ambient air sensed by insects. For decades, EAG recording has been coupled with GC analysis, where volatiles are heated to 
temperatures around $350^{\circ} \mathrm{C}$ (Aglient, 2017), and after column separation, the EAG response to each analyte allows the identification of possible bioactive compounds within a mixture. The only other report we have found that combines EAG with sample heating is from Zwiebel and Pask (2016), who demonstrated that thermal volatilization by propane torch increased the EAG response of Anopheles gambiae to VUAA1 , a presumptive repellent. However, the pipette and sample temperature in this study was not monitored and temperaturecontrolled heating by flame in an EAG system is difficult at best. In the present study, electrical coil induction heating was employed for faster, economical, and controllable thermal volatilization of compounds for EAG recording.

Induction heating was invented in 1922 and is used frequently in modern manufacturing processes for metal bonding, softening, welding, and melting (Rudnev et al., 2017). A typical induction heater consists of an electromagnet connected to an electronic oscillator that can generate a low voltage and high alternating current $(\mathrm{AC})$ through the electromagnet. Induction heating systems utilize the Joule heating effect, where eddy currents generated from the high $\mathrm{AC}$ and magnetic hysteresis losses will produce mass heat in ferromagnetic objects, but not other materials (Rudnev et al., 2017). Paramagnetic materials (e.g., aluminum, copper) will not be heated efficiently with no magnetic hysteresis losses and low resistivity. The induction heating technique is the most efficient, repeatable, and precise heating method used in modern industry (Lucía et al., 2014), having a $9.8 \%$ increase of heating efficiency when compared with other methods (Department of Energy, 2013). As an electrically controlled system, once the positions of the induction heater and the metal element are fixed, the heating effect can be precisely controlled by the voltage applied to the electromagnet. The aim of this study was to build a coupled induction heating coilelectroantennography (IH-EAG) system, which not only allowed fast and precisely controlled heating of chemical samples, but also ensured a negligible increase (no more than $1^{\circ} \mathrm{C}$ ) of the air delivery temperature to the insect antenna.

\section{MATERIALS AND METHODS}

\section{Description of the Coupled IH-EAG System}

A $5-12 \mathrm{~V}$ ZVS low voltage induction heating power supply module with a coil (Chunghop Electronics IND CO LTD, Guangzhou, China) served as the induction heater (Figure 1A). A digital automation delay timer/switch (HeroNeo, $12 \mathrm{~V}$ Home Automation Delay Timer Control Switch Module Digital Display LED from Amazon on-line) was used for heating time control (Figure 1B). A treated filter paper strip, or alternatively a glass fiber filter or strip of aluminum foil, was threaded onto a stainless carbon steel wire (Beading wire, Hobby Lobby, Auburn AL, USA), and then inserted into a glass Pasteur pipette (Figure 1C) $15 \mathrm{~cm}$ in length and $0.6 \mathrm{~cm}$ in diameter (Fisher Scientific, Pittsburgh, Pennsylvania, USA). The tip of the pipette was connected to one end of a "T" type glass connector and directed to the antennal preparation (Figure 1D). The outlet of a continuous air flow was attached to the glass connector at the other end (Figure 1D). To heat chemical samples on the filter paper strip, the pipette was fixed in the middle of the heating coil, and sufficient current was passed for a certain time period to reach the expected wire temperature before a stimulus air puff (1s). Only the part of the carbon steel wire within the coil is heated by the current, thus improving the heating precision and minimizing the thermal effect on ambient temperature.

For recording EAG responses, one antenna was amputated at the base and the distal tip was removed with a scalpel. Each end of the antenna was immediately anchored to a metal electrode with non-drying electrode gel (Spectra 360 Electrode Gel, Parker Laboratories, INC. Fairfield, NJ). The electrodes were connected through a high-impedance DC amplifier. The signal was processed through a four-channel serial-bus acquisition controller (IDAC4, Syntech, Hilversum, Netherlands) and analyzed with software (EAG Pro from Syntech). A continuous flow rate $(0.6 \mathrm{~L} / \mathrm{min})$ of humidified air was provided by a stimulus controller (CS-05, Syntech). A $120 \mathrm{~s}$ interval between successive stimulations was allowed for antennal recovery. A schematic picture of the entire system is shown in Figure 1D.

\section{Heating Calibration}

Carbon steel wires of 20 - and 26-gauge were chosen as the heating filaments. To calibrate the heating profile of the wires, different voltages $(4.5-10 \mathrm{~V})$ were applied to the coil, and the temperature increase over time was recorded by bonding to a thermocouple (initially calibrated by the manufacturer, temperature range: -200 to $1,260^{\circ} \mathrm{C}$, TMD-52, AMPROBE, Everett, WA, USA). The thermocouple was coated with a layer of silicone grease heat sink (BAB-680, Fujik, from Amazon.com) to reduce the thermocouple temperature increase and improve the heat conducting efficiency from wire to thermocouple when calibrated with 20-gauge wire, but not with 26-gauge wire because the thinner wire was heated beyond the operating capacity of the grease (recommended use below $200^{\circ} \mathrm{C}$ ). The thermocouple temperature and induction heating coil temperature were measured alone without the presence of carbon steel wire to confirm the feasibility of using a thermocouple to calibrate the wire temperature. The aluminum foil and filter paper temperatures were measured by wrapping it around an alcohol thermometer to test whether a paramagnetic or non-metallic material alone was heated by the coil. The temperature change of the airstream delivered to the antenna was measured in separate studies by inserting the thermocouple into the outlet of the air flow pipette. Each type of wire was tested at each voltage three times (replicates) and recorded for at least $15 \mathrm{~s}$; the wire was replaced with a new one for every replicate to control for any material bias.

\section{EAG Response in Coupled Induction Heating-Electroantennogram System Insects and Chemicals}

The species of mosquito used for the IH-EAG tests was the insecticide susceptible Orlando strain of Aedes aegypti, established in 1952. This colony is maintained at the United States Department of Agriculture-Agricultural Research Services, Center for Medical, Agricultural, and Veterinary Entomology (USDA-ARS CMAVE) in Gainesville, FL. Newly 

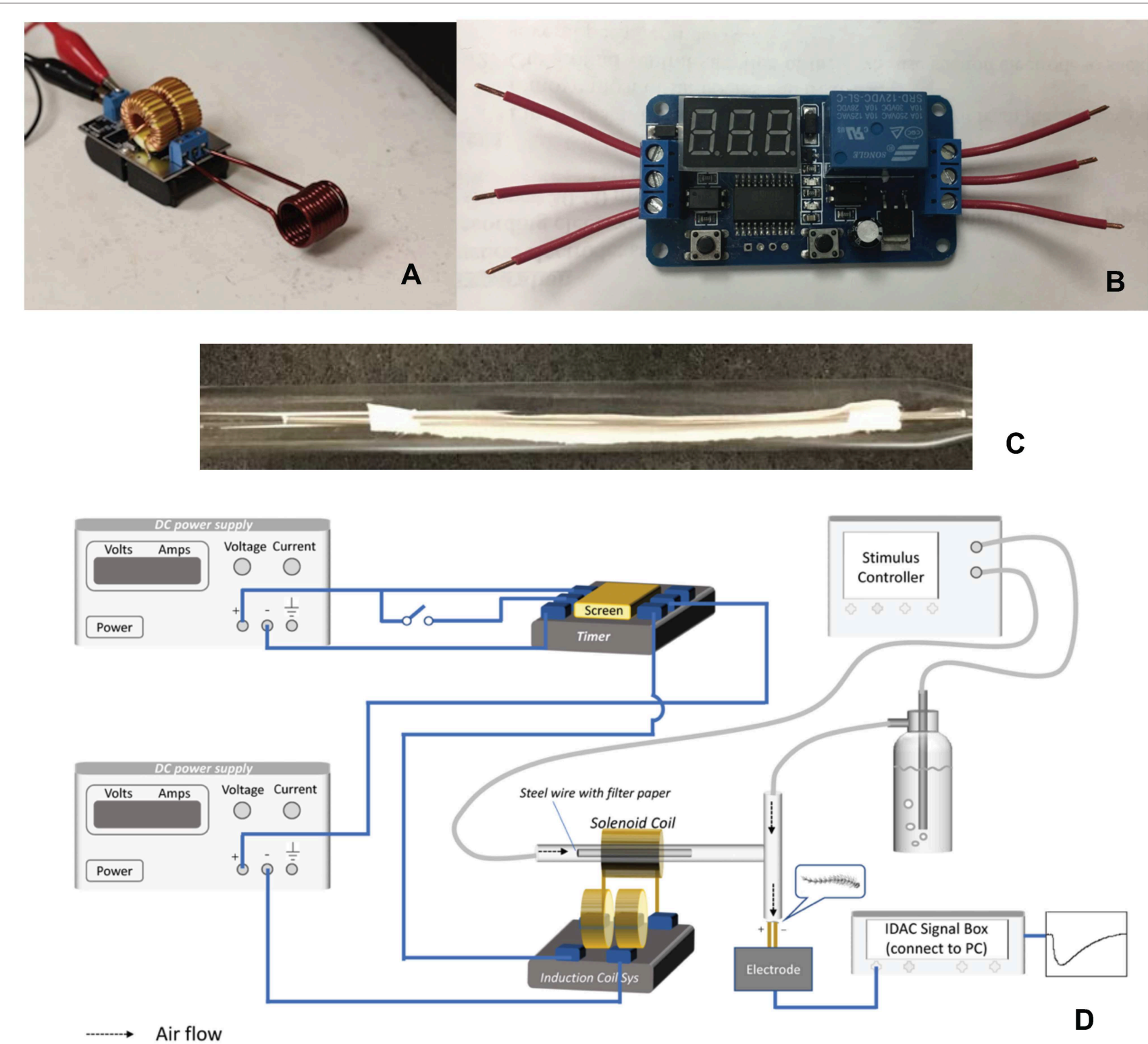

FIGURE 1 | Components of the coupled IH-EAG system. (A) The induction heating solenoid coil. (B) The digital timer. (C) Photograph of an assembled wire with filter paper within the glass pipette that is part of the air delivery tubing. (D) Diagrammatic illustration of the complete system.

emerged adults were held in framed mesh cages $(20 \times 20 \times$ $20 \mathrm{~cm}$ ) (Bugdorm TM, BioQuip Products, Rancho Dominguez, CA, USA) supplied with $10 \%$ sugar water, and kept under $28 \pm$ $1{ }^{\circ} \mathrm{C}, 75 \% \mathrm{RH}$, and 12:12 (L:D) h photoperiod. Non-blood fed 4-7 day old adult female antennae were used for the EAG tests. The chemicals used for EAG heating tests were the standard repellent, N, N-diethyl-3-methylbenzamide, DEET (97\%, Sigma-Aldrich Chemical Co. St. Louis, MO, USA), the attractant, 1-octen-3-ol (> 98\%, Sigma-Aldrich Chemical Co.), and the candidate repellent compound VUAA-1 (Jones et al., 2011) was custom synthesized to high purity (>99\%, Princeton Biomolecular Research, Princeton, NJ, USA). Though the olfactory response of mosquitos to DEET and 1-octen-3-ol have mostly been recorded from maxillary palp, the antennal responses to these two compounds (Stanczyk et al., 2010) and VUAA-1(Zwiebel and Pask, 2016) have also been reported.

\section{DEET and 1-octen-3-ol Heating}

To test the efficacy of the IH-EAG system, $10 \mu \mathrm{L}$ of liquid DEET or 1-octen-3-ol in $10 \mu \mathrm{L}$ of acetone solution were applied to a filter paper strip $\left(0.8 \times 5 \mathrm{~cm}^{2}\right.$, Fisher Scientific, Pittsburgh, PA) threaded onto a piece of wire, and at least $1 \mathrm{~min}$ was allowed for solvent evaporation before it was placed into the glass pipette. EAG responses to clean air (blank) and evaporated acetone paper strip were tested as negative controls. EAG response of $0.1 \mathrm{mg}$, and $1 \mathrm{mg}$ of DEET and 1-octen-3-ol were measured without/with 

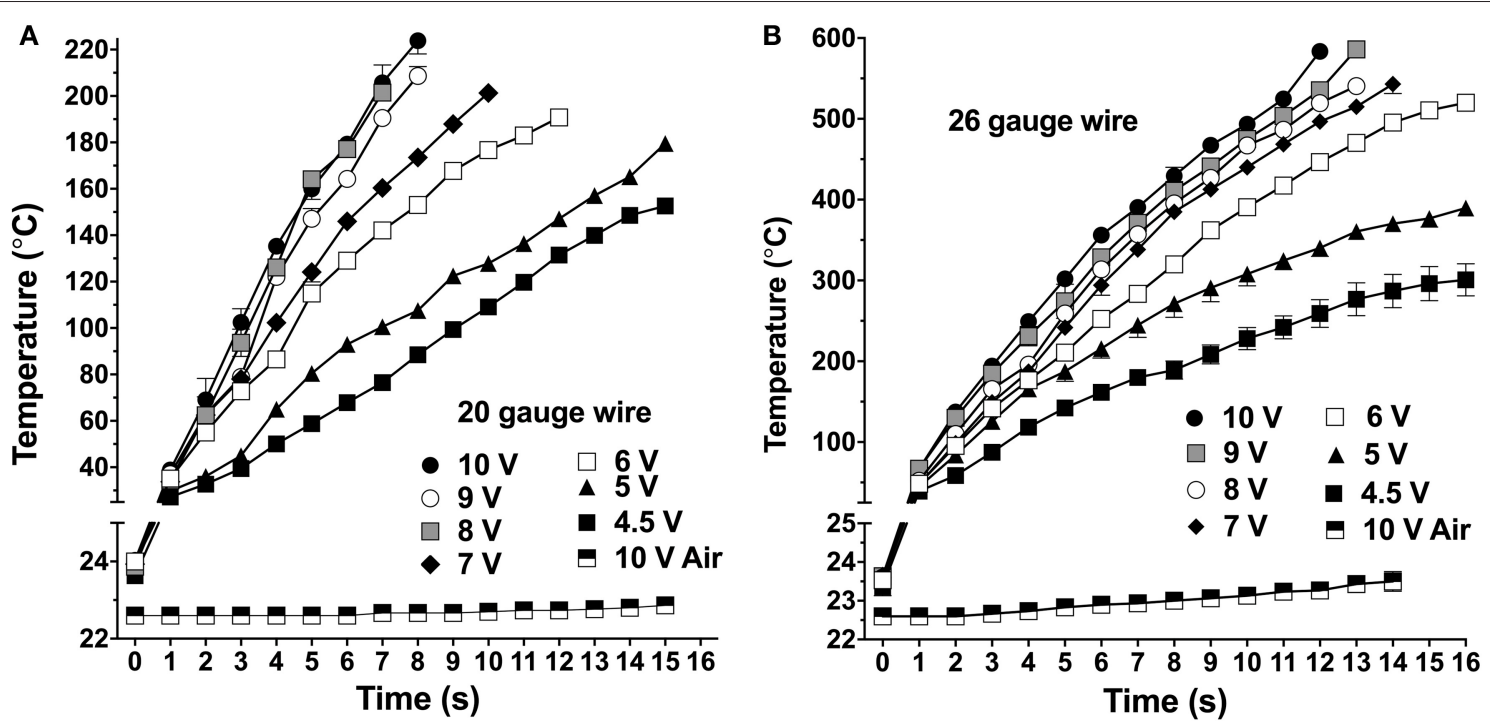

FIGURE 2 | Temperature changes in two gauges of wire at different applied voltages. (A) 20-gauge wire. (B) 26-gauge wire. Air delivery temperature at the mouth of the application pipette was measured using the highest induction heating voltage, designated "10 V Air" in both plots. Symbols are mean \pm SEM; symbols apparently lacking error bars is because they are within the size of the symbol.

heating using different filter papers. A 20-gauge wire was used for heating most samples. EAG recordings for each chemical were obtained from at least seven antennae, each removed from a different female. EAG responses to volatiles were calculated as corrected EAG values by subtracting the matched blank response. EAG amplitudes that were lower than blank amplitudes were considered no EAG response and adjusted to $0 \mathrm{mV}$. The data were then compared by unpaired $t$-test using GraphPad Prism 7.0 software (GraphPad Software, Inc., San Diego, CA, USA).

\section{VUAA-1 Heating}

Ten milligram of VUAA-1 was dissolved in $500 \mu \mathrm{L}$ of acetone and then applied to the filter paper strip as 20 aliquots of $25 \mu \mathrm{L}$ of solution because of its low solubility in organic solvents. The treated filter paper was then placed in a fume hood to evaporate for $2 \mathrm{~h}$ before testing. A 26-gauge wire was chosen for VUAA1 heating, because no significant EAG responses were obtained when heated to $100^{\circ} \mathrm{C}$ in preliminary tests. To prevent any bias from scorching of the filter paper, glass fiber filter $\left(0.8 \times 5 \mathrm{~cm}^{2}\right.$, Whatman, Pittsburgh, PA) and aluminum foil were considered as alternate sample platforms. Accordingly, the heating effect on antennal responses to untreated negative controls (wire, normal filter paper, glass fiber filter, and aluminum foil) were tested and compared with that from an empty pipette to ensure responses could account for any differences in materials. The EAG responses from all tested negative controls are presented as raw data (no correction from blank control). These data were analyzed using Analysis of Variance (ANOVA) followed by a Tukey's Honestly Significant Difference (HSD) test (alpha = 0.05 ) for comparison with heating effects on untreated negative controls. Temperature-dependent responses of VUAA-1 were thus obtained using glass fiber filter or aluminum foil threaded onto the heating wire, because at high temperatures, filter paper proved unsuitable. EAG responses were obtained for each substrate from at least seven antennae, and responses to VUAA1 were calculated as corrected EAG values as aforementioned at temperatures from 25 to $500^{\circ} \mathrm{C}$. Data for each material across temperatures were analyzed by ANOVA as described above, and the EAG responses for VUAA-1 on glass fiber filter and aluminum foil were compared using an unpaired $t$-test. Additionally, the weights of VUAA-1 on treated aluminum foil (10 mg) were compared before and after heating to assess the amount of compound volatilized (mean \pm SEM).

To test whether any decomposition of VUAA-1 occurred after sample heating, the substrate was extracted with acetone right after heating, and compared with samples extracted at room temperature $\left(25^{\circ} \mathrm{C}\right)$. To accomplish this, the heating filament and tinfoil were suspended in acetone $(5 \mathrm{~mL})$ for $2 \mathrm{~h}$. The acetone was decanted off, and the heating filament and tinfoil were washed with acetone $(2 \times 5 \mathrm{~mL})$. All the organic layers were collected, and the solvent was removed under reduced pressure. The residue was then placed under a steady stream of air to ensure the complete removal of solvent. The resulting solid was taken directly to ${ }^{1} \mathrm{H}-\mathrm{NMR}$ without further purification.

\section{RESULTS}

\section{Heating Efficiency of IH-EAG System}

The induction heating system produced stable temperature control (coefficient of variation, $\mathrm{CV}<10 \%$ at all time points) from 25 to $225^{\circ} \mathrm{C}$ for the 20-gauge wire (Figure 2A), and up to $600^{\circ} \mathrm{C}$ with the 26-gauge wire (Figure 2B), when the coil was driven at different AC voltages from 4.5 to $10 \mathrm{~V}$. The 20gauge wire was used for heating samples up to $225^{\circ} \mathrm{C}$, and $10 \mathrm{~V}$ (CV: 1.35-9.27\%) was selected for EAG tests. When driven 
by $10 \mathrm{~V}$ for $4 \mathrm{~s}$, the 20 -gauge wire temperature reached $135 \pm$ $2.7^{\circ} \mathrm{C}$ (mean $\pm \mathrm{SEM}$ ). The 26-gauge wire was used for heating samples up to $600^{\circ} \mathrm{C}$, and $6 \mathrm{~V}$ (CV: $\left.1.13-8.38 \%\right)$ was selected for EAG tests. Within $15 \mathrm{~s}$ at $6 \mathrm{~V}, 26$-gauge wire can be heated to $500 \pm 8^{\circ} \mathrm{C}$. Moreover, the temperature change of the air delivered to the antennae increased by no more than about $1^{\circ} \mathrm{C}$ (Figures 2A,B). The induction heating coil, thermocouple, filter paper, aluminum foil, and alcohol thermometer temperature were also calibrated (Figures S1A,B). Compared to the wire temperature, the temperature increase of the coil, aluminum foil, and thermocouple were significantly lower, suggested that using thermocouple for the wire calibration is feasible, and any heat contributed to the chemical sample by the coil and aluminum foil were far less than the heat generated by the wire. The alcohol thermometer and filter paper were not heated by the induction coil because they are non-metallic materials.

\section{EAG Response in Coupled Induction Heating-Electroantennogram System}

The coupled induction heating system was used to test the EAG responses of adult female Ae. aegypti antennae to mosquito repellents and an attractant (Figure 3A). When heated to $135^{\circ} \mathrm{C}$, the EAG response to $0.1 \mathrm{mg}$ of DEET increased significantly 3 fold from $0.11( \pm 0.03)$ to $0.33( \pm 0.05) \mathrm{mV}(t=3.87, \mathrm{df}=14, P=$ $0.002)$, and was virtually equal to the EAG response of $1 \mathrm{mg}(0.34$ $\pm 0.05 \mathrm{mV})(F=0.81, \mathrm{df}=2,19, P=0.46)$ at room temperature (Figure 3A). The EAG response to $1 \mathrm{mg}$ DEET showed no significant change in amplitude with or without heat $(t=0.02$, $\mathrm{df}=12, P=0.986)$. Likewise, Ae. aegypti antennae showed a 4.4-fold increase of EAG response to $0.1 \mathrm{mg}$ of 1-octen-3-ol after heating $(0.57 \pm 0.13 \mathrm{mV})$ compared to the sample at room temperature $(0.13 \pm 0.03 \mathrm{mV})(t=3.38, \mathrm{df}=12, P=0.005)$. The response to $0.1 \mathrm{mg}$ with heat was equal to $1 \mathrm{mg}$, indicating a 10 fold increase in efficiency of compound delivery. There was no significant change observed for $1 \mathrm{mg}$ of 1 -octen-3-ol with $(0.60$ $\pm 0.12 \mathrm{mV})$ or without heat $(0.62 \pm 0.12 \mathrm{mV})(t=0.1, \mathrm{df}=12, P$ $=0.923$ ) (Figure 3A). Figure 3B shows that the EAG response to the heated filter paper control $(0.42 \pm 0.05 \mathrm{mV})$ increased significantly, while no significant differences were observed among an empty pipette $(0.23 \pm 0.03 \mathrm{mV}), 26$-gauge wire alone $(0.20 \pm 0.03 \mathrm{mV})$, glass fiber $(0.19 \pm 0.06 \mathrm{mV})$, and aluminum foil $(0.34 \pm 0.04 \mathrm{mV})(F=5.641, \mathrm{df}=4,29, P=0.002)$. When VUAA-1 was applied to glass fiber filters and heated, the EAG response increased significantly with temperature up to $400^{\circ} \mathrm{C}$ (Figure 3C). However, the EAG response declined when heated to $500^{\circ} \mathrm{C}(1.67 \pm 0.26 \mathrm{mV})$ and was significantly less than the response at $400^{\circ} \mathrm{C}(6.40 \pm 0.74 \mathrm{mV})(F=58.11, \mathrm{df}=$ 5 , 36, $P<0.001)$. Similarly, heating of aluminum foil showed significantly increased responses at all tested temperatures $(F=$ $79.85, \mathrm{df}=5,36, P<0.001)$. When comparing EAG responses of both materials at a matched temperature, aluminum foil showed significantly greater efficiency of VUAA-1 delivery than glass fiber at $100^{\circ} \mathrm{C}(t=2.99, \mathrm{df}=12, P=0.011), 200^{\circ} \mathrm{C}(t=$ 3.58 , df $=12, P=0.004), 300^{\circ} \mathrm{C}(t=6.63$, df $=12, P<$ $0.001)$, and $500^{\circ} \mathrm{C}(t=8.62, \mathrm{df}=12, P<0.001)$. No significant difference was observed between glass fiber filter and aluminum

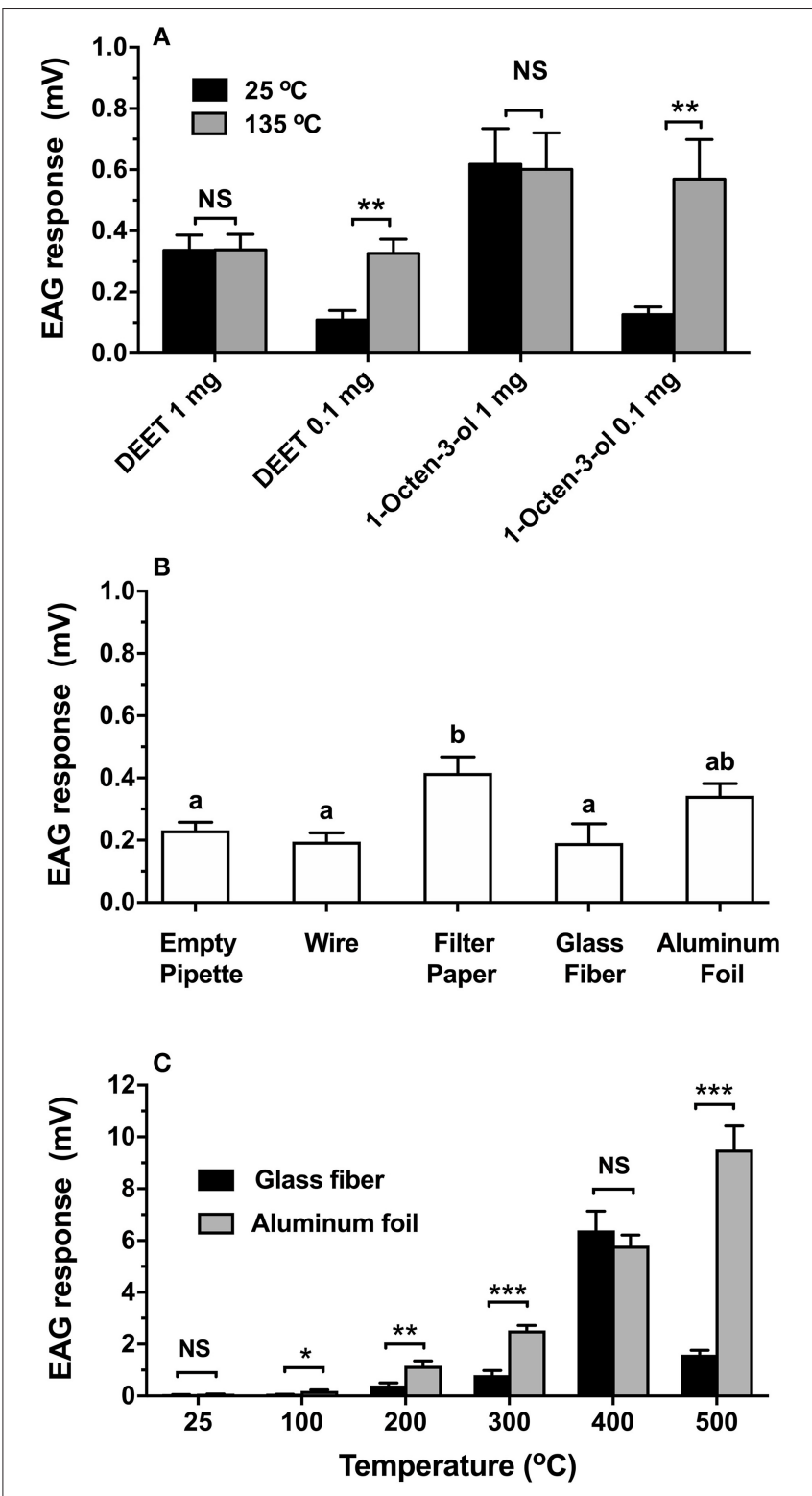

FIGURE 3 | Heating effects on EAG responses of selected compounds and materials. In all cases, bars are means $(n \geq 7) \pm$ SEM. (A) DEET and 1-octen-3-ol responses using 20-gauge wire. Statistical significance between responses at 25 and $100^{\circ} \mathrm{C}$ was determined by t-test. Asterisks indicate ${ }^{* *} p<$ 0.01. (B) Untreated wire with filter paper, glass fiber filter, and aluminum foil heated to $500^{\circ} \mathrm{C}$ using 26 -gauge wire; responses compared by ANOVA and Tukey's HSD test. Bars labeled by the same letter are not significantly different (alpha $=0.05)$. (C) Temperature-dependent responses of VUAA-1 using 26-gauge wire when applied to a glass fiber filter or aluminum foil. Statistical significance of responses at different temperatures were compared by ANOVA and Tukey's HSD test. Bars labeled by the same lower-case letter (glass fiber) or capitol letter (aluminum foil) are not significantly different (alpha $=0.05$ ). Significance difference in responses between materials at each temperature was determined by t-test; asterisks indicate ${ }^{*} p<0.05$, ${ }^{* \star} p<0.01$, and ${ }^{* \star *} p<0.001$.

foil when VUAA-1 was tested at room temperature $(t=0.69$, $\mathrm{df}=12, P=0.506)$, or when heated to $400^{\circ} \mathrm{C}(t=0.70, \mathrm{df}=$ $12, P=0.498)$. 
Because VUAA-1 required such high temperatures to show EAG activity, the amount of VUAA-1 loss from aluminum foil after heating to 200 and $500^{\circ} \mathrm{C}$ were compared to that at room temperature. An average of $0.063 \pm 0.019 \mathrm{mg}$ of weight loss $(0.57 \%$ of the applied weight $)$ was observed by heating to $200^{\circ} \mathrm{C}$ and $0.140 \pm 0.012 \mathrm{mg}$ of weight loss ( $1.41 \%$ of applied weight) by heating to $500^{\circ} \mathrm{C}$. No weight loss was detected when treated at room temperature. Furthermore, though the VUAA-1 sample became a yellow liquid after heating to $500^{\circ} \mathrm{C}$, no decomposition of VUAA-1 was observed as the ${ }^{1} \mathrm{H}-\mathrm{NMR}$ spectra indicated a return of starting reagent with $>99.9 \%$ purity (Figure 4).

NMR spectra were obtained on a Varian Inova $500 \mathrm{MHz}$ spectrometer at $500\left({ }^{1} \mathrm{H}\right)$ and $126\left({ }^{13} \mathrm{C}\right) \mathrm{MHz}$. The chemical shifts for ${ }^{1} \mathrm{H}$ and ${ }^{13} \mathrm{C}$ are reported in $\delta(\mathrm{ppm})$ against tetramethylsilane as an internal standard for reference, and coupling constants are given in $\mathrm{Hz}$. Deuterated solvents were purchased from Cambridge Isotope Laboratories. The following abbreviations are used to show coupling in the spectra: $s$ (singlet), $d$ (doublet), $t$ (triplet), q (quartet), and $\mathrm{m}$ (multiplet). The spectra values for VUAA-1 recovered from assay run at different temperature were as follows.

$25^{\circ} \mathrm{C}:{ }^{1} \mathrm{H}$ NMR $(500 \mathrm{MHz}$, Chloroform-d) $\delta 10.23(\mathrm{~s}, 1 \mathrm{H})$, $8.89(\mathrm{~d}, J=1.4 \mathrm{~Hz}, 1 \mathrm{H}), 8.81(\mathrm{dd}, J=4.9,1.6 \mathrm{~Hz}, 1 \mathrm{H}), 8.00(\mathrm{ddd}$, $J=8.0,1.6,1.4 \mathrm{~Hz}, 1 \mathrm{H}), 7.56-7.49(\mathrm{~m}, 3 \mathrm{H}), 7.13(\mathrm{~d}, J=8.4 \mathrm{~Hz}$, $2 \mathrm{H}), 4.07(\mathrm{~s}, 2 \mathrm{H}), 4.03(\mathrm{q}, J=7.3 \mathrm{~Hz}, 2 \mathrm{H}), 2.60(\mathrm{q}, J=7.6 \mathrm{~Hz}$, $2 \mathrm{H}), 1.41(\mathrm{t}, J=7.3 \mathrm{~Hz}, 3 \mathrm{H}), 1.20(\mathrm{t}, J=7.6 \mathrm{~Hz}, 3 \mathrm{H})$.

200 ${ }^{\circ} \mathrm{C}:{ }^{1} \mathrm{H}$ NMR $(500 \mathrm{MHz}$, Chloroform-d) $\delta 10.23(\mathrm{~s}, 1 \mathrm{H})$, $8.89(\mathrm{~d}, J=1.4 \mathrm{~Hz}, 1 \mathrm{H}), 8.81(\mathrm{dd}, J=4.9,1.6 \mathrm{~Hz}, 1 \mathrm{H}), 8.00(\mathrm{ddd}$,
$J=8.0,1.6,1.4 \mathrm{~Hz}, 1 \mathrm{H}), 7.56-7.49(\mathrm{~m}, 3 \mathrm{H}), 7.13(\mathrm{~d}, J=8.4 \mathrm{~Hz}$, $2 \mathrm{H}), 4.07$ (s, $2 \mathrm{H}), 4.03(\mathrm{q}, J=7.3 \mathrm{~Hz}, 2 \mathrm{H}), 2.60(\mathrm{q}, J=7.6 \mathrm{~Hz}$, $2 \mathrm{H}), 1.41$ (t, $J=7.3 \mathrm{~Hz}, 3 \mathrm{H}), 1.20(\mathrm{t}, J=7.6 \mathrm{~Hz}, 3 \mathrm{H})$.

$500^{\circ} \mathrm{C}:{ }^{1} \mathrm{H}$ NMR $(500 \mathrm{MHz}$, Chloroform-d) $\delta 10.22(\mathrm{~s}, 1 \mathrm{H})$, $8.89(\mathrm{~d}, J=1.4 \mathrm{~Hz}, 1 \mathrm{H}), 8.81(\mathrm{dd}, J=4.9,1.6 \mathrm{~Hz}, 1 \mathrm{H}), 8.01$ (ddd, $J=8.0,1.6,1.4 \mathrm{~Hz}, 1 \mathrm{H}), 7.56-7.49(\mathrm{~m}, 3 \mathrm{H}), 7.13(\mathrm{~d}, J=8.4 \mathrm{~Hz}$, $2 \mathrm{H}), 4.07(\mathrm{~s}, 2 \mathrm{H}), 4.03(\mathrm{q}, J=7.3 \mathrm{~Hz}, 2 \mathrm{H}), 2.60(\mathrm{q}, J=7.6 \mathrm{~Hz}$, $2 \mathrm{H}), 1.41(\mathrm{t}, J=7.3 \mathrm{~Hz}, 3 \mathrm{H}), 1.20(\mathrm{t}, J=7.6 \mathrm{~Hz}, 3 \mathrm{H})$.

\section{DISCUSSION}

Our IH-EAG system allows precise temperature control from room temperature to $600^{\circ} \mathrm{C}$ with little effect on the temperature change of the air delivered to the antennae. When heated to $135^{\circ} \mathrm{C}$, both DEET and 1-octen-3-ol showed a 10-fold increase in efficiency, with the response to $0.1 \mathrm{mg}$ with heat equal to $1 \mathrm{mg}$ at room temperature, clearly because the odorant receptor response was maximal at $1 \mathrm{mg}$ for both compounds at room temperature. The results suggest that the coupled IH-EAG system can increase significantly the efficiency of EAG testing by reducing the amount of compound required for assessing antennal receptor activation, and it is compatible with single cell mesurements, as well. Further, the method also makes it possible to compare the responses of different odorants at environmentally-relevant temperatures under the same heating profile, expressed as area under the heating curve in degrees-sec. Of course, any heating paradigm must consider the thermal lability of the material under study.

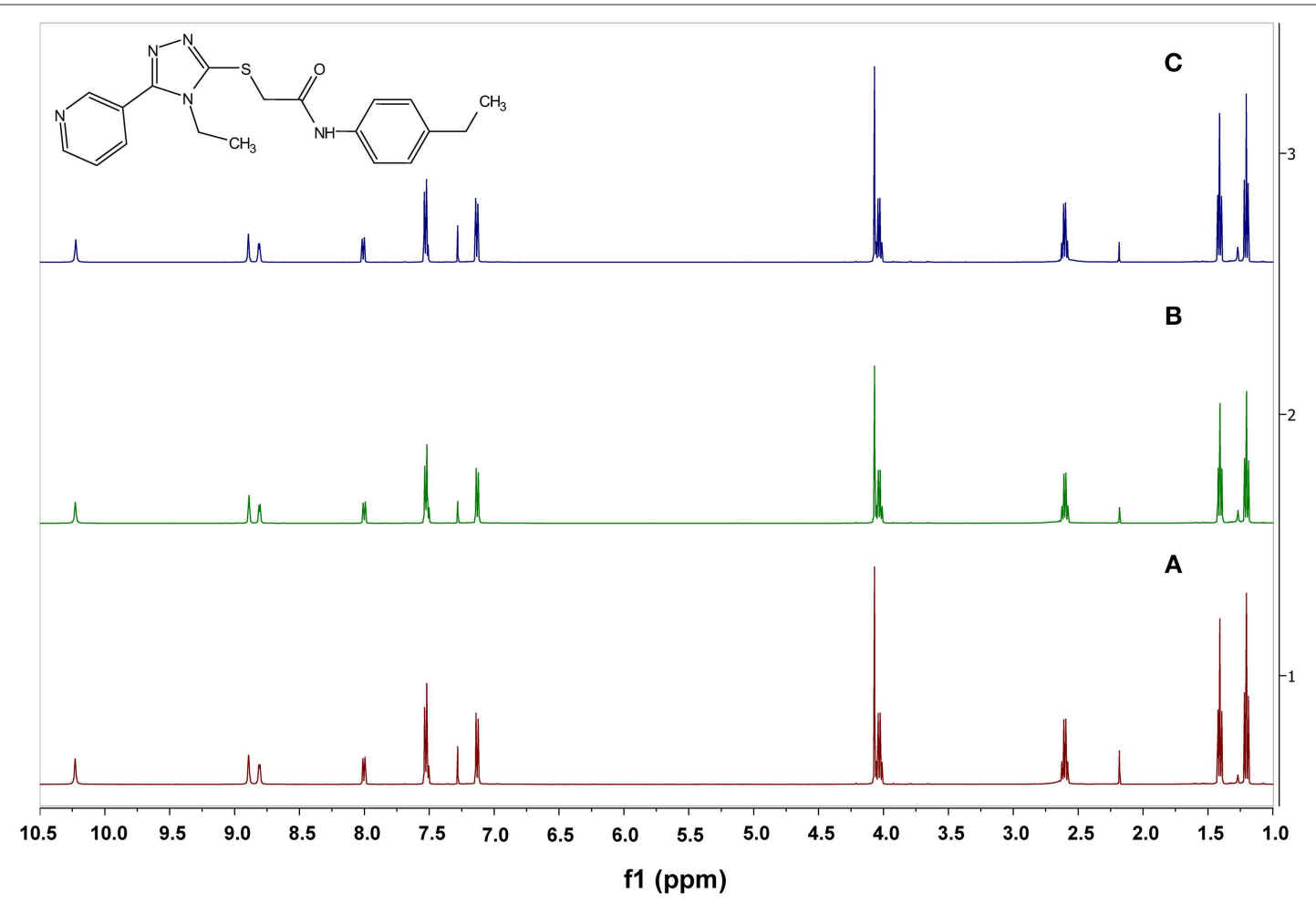

FIGURE $4 \mid{ }^{1} \mathrm{H}-\mathrm{NMR}$ spectra of acetone-extracted VUAA-1 samples. (A). Sample extracted at room temperature. (B) Sample extracted after heating to $200^{\circ} \mathrm{C}$ using the induction heating for $4 \mathrm{~s}$ at $6 \mathrm{~V}$. (C) Sample extracted after heated to $500^{\circ} \mathrm{C}$ with induction heating for $15 \mathrm{~s}$ at $6 \mathrm{~V}$. 
Three different materials were tested in our studies as controls (Figure 3B). When heated to $500^{\circ} \mathrm{C}$, any increased EAG response with filter paper might due to combustion products, such as heat or $\mathrm{CO}_{2}$. No significant differences in EAG responses were observed among an empty pipette, glass fiber, and aluminum foil. This result suggested that glass fiber and aluminum foil may serve as better treatment surfaces if a high temperature is required. When tested with VUAA1 , our results are consistent with those of Zwiebel and Pask (2016), who showed that thermal volatilization by propane torch can increase the EAG response of An. gambiae to VUAA1 when loaded directly into a glass pipette. In our study, the EAG response to VUAA-1 on glass fiber filters increased significantly with temperature up to $400^{\circ} \mathrm{C}$, but declined substantially when heated to $500^{\circ} \mathrm{C}$. This decline probably occurred because the borosilicate glass reached its transition temperature (around $525^{\circ} \mathrm{C}$ ), changing the glass fiber from glassy to viscous state (Merz et al., 2003), and thus decreasing the amount of VUAA-1 released. Overall, aluminum foil had greater delivery efficiency than glass fiber filters (Figure 3C). Moreover, the weight loss measurements correlated with the increased EAG responses of VUAA-1 with heating, and ${ }^{1} \mathrm{H}$ NMR spectra results confirmed that no decomposition occurred when VUAA-1 was heated up to $500^{\circ} \mathrm{C}$ within $15 \mathrm{~s}$. Though the amount of chemical released cannot be equated to the amount reaching the antenna, the results demonstrate that the IH-EAG system can significantly increase the sensitivity of EAG measurements to low volatility compounds, such as VUAA1 , which showed no appreciable evaporation or EAG response at $25^{\circ} \mathrm{C}$.

The data shown here confirm several experimental advantages anticipated for the IH-EAG system. First, this method allows sample heating up to $600^{\circ} \mathrm{C}$, and the rapid cooling character of steel wire minimizes the airstream temperature change to about to $1^{\circ} \mathrm{C}$. Secondly, as an electrically driven system, temperature can be accurately controlled by the choices of wire, voltage, and heating time. The IH-EAG system also allows temperature control from ambient to $100^{\circ} \mathrm{C}$, or less, by using lower gauge, thicker wire (such as 10,14- gauge wire), and appropriate voltages/heating times. The power supply needed for this induction heating coil is $12 \mathrm{~V}$, which is safe to use and can even be replaced by alkaline batteries, if needed. In the IH-EAG system, typical filter paper can be used to test compounds up to $200^{\circ} \mathrm{C}$ and glass fiber filter allows testing up to $400^{\circ} \mathrm{C}$. The results show that aluminum foil can be used up to $600^{\circ} \mathrm{C}$, and it has excellent ductility, corrosion resistance, and heat conduction when in contact with the steel wire heating element. Compounds could possibly be applied to a ribbon of ferromagnetic metal directly acting as the heating element, but this was approach was not attempted. Though the established GC-EAD method can heat volatiles to identify bioactive compounds, it less efficient for testing single chemicals on antennae because of the high cost, column maintenance, temperature limitation, and slow heating speed. For a typical GC system, the maximum temperature is $350^{\circ} \mathrm{C}$ with a maximum ramp rate of $30^{\circ} \mathrm{C} / \mathrm{min}$ (Aglient, 2017). Induction heating also has advantages over typical resistance heating for this application. Resistance heating would have to employ wires for current delivery, and complicate assembling the apparatus within air flow tubing or pipette, whereas the IH system only requires fixing the pipette within the induction coil (Figure 1). Moreover, the IH system specifically confines the heating area to the wire encircled by the coil, instead of running heating current through the whole wiring circuit. Because of these advantages, the $\mathrm{IH}$ system could also be used to volatilize chemicals for other bioassays in a confined space, such as Y-tube olfactometer, or vapor phased spatial repellency/attractance arena. Moreover, if a constant temperature is needed, a thermostat can be connected to the inductionheating coil instead of the timer, which may advance the use of induction heating in other types of bioassays. In conclusion, the coupled IH-EAG system is relatively easy to assemble, compatible with existing olfactory research equipment configurations, inexpensive ( $<\$ 25$ at current prices), and is a significant advance for chemical testing of antennal responses in insects and other animals.

\section{DATA AVAILABILITY}

All datasets generated for this study are included in the manuscript.

\section{AUTHOR CONTRIBUTIONS}

LY, YL, and JB: conceptualization. LY, YL, and GR: investigation. UB and KL: resources. LY: data curation and writing-original draft preparation. $\mathrm{KL}$ and JB: review and editing. JB: supervision, project administration, and funding acquisition.

\section{FUNDING}

This project was funded by the Department of Defense, Deployed War Fighter Research Program, under USDA Specific Cooperative Agreements 59-603608-001 and 58-0208-5-001 to JB.

\section{ACKNOWLEDGMENTS}

We thank Shiyao Jiang for critical review of the manuscript, Dr. Quentin Coquerel for suggesting the use of silicon grease in the calibration experiments, and Dr. Dan Kline of the USDA-ARS CMAVE for providing the Ae. aegypti mosquitoes.

\section{SUPPLEMENTARY MATERIAL}

The Supplementary Material for this article can be found online at: https://www.frontiersin.org/articles/10.3389/fevo. 2019.00247/full\#supplementary-material

Figure S1 | Temperature changes in different materials caused by $10 \mathrm{~V}$ (A) or $6 \mathrm{~V}$ (B), and to 20 and 26-gauge wires, respectively. Temperature calibrations were performed on a glass alcohol thermometer alone in the induction coil (Black squares), of the induction heating coil itself measured by a thermocouple on its outside surface (gray squares), of filter paper (white triangles in $\mathbf{A}$ ) or aluminum foil 
(white triangles in $\mathbf{B}$ ) wrapped around the alcohol thermometer, of the thermocouple coated with thermal grease (black triangles in $\mathbf{A}$ ), of a 20 gauge wire in contact with the thermocouple via heat-conducting grease (white circles in $\mathbf{A}$ ), of the thermocouple alone black triangles in $\mathbf{B}$, and of the thermocouple attached to the carbon steel wire (white circles in $\mathbf{B}$ ). Symbols are mean \pm SEM; symbols apparently lacking error bars is because they are within the size of the symbol.

\section{REFERENCES}

Aglient (2017). Agilent 7820A Gas Chromatograph System. Available online at: https://www.agilent.com/cs/library/datasheets/public/5991-5345EN.pdf (accessed June 10, 2019).

Department of Energy (2013). Energy Conservation Program: Test Procedures for Conventional Cooking Products With Induction Heating Technology. Available online at: https://www.energy.gov/sites/prod/files/2016/08/f33/Conventional \%20Cooking\%20Products\%20TP\%20SNOPR.pdf (accessed April 17, 2019).

Jones, P. L., Pask, G. M., Rinker, D. C., and Zwiebel, L. J. (2011). Functional agonism of insect odorant receptor ion channels. Proc. Natl. Acad. Sci. U.S.A. 108, 8821-8825. doi: 10.1073/pnas.1102425108

Lucía, O., Maussion, P., Dede, E. J., and Burdío, J. M. (2014). Induction heating technology and its applications: past developments, current technology, and future challenges. IEEE Trans. Ind. Electron. 61, 2509-2520. doi: 10.1109/TIE.2013.2281162

Ma, G., Hoffman, A., and Ma, C.-S. (2015). Daily temperature extremes play an important role in predicting thermal affects. J. Exp. Biol. 218, 2289-2296. doi: $10.1242 /$ jeb. 122127

Merz, P., Quenzer, H. J., Bernt, H., Wanger, B., and Zoberbier, M. (2003). “A novel micromachining technology for structuring borosilicate glass substrates," in TRANSDUCERS '03. 12th International Conference on Solid-State Sensors, Actuators and Microsystems. Digest of Technical Papers, Vol. 1 (Boston, MA: IEEE), 258-261.

Myrick, A. J., and Baker, T. C. (2018). Increasing signal-to-noise ratio in gas chromatography - electroantennography using a deans switch effluent chopper. J. Chem. Ecol. 44, 111-126. doi: 10.1007/s10886-017-0916-y

Ng, R., Lin, H.-H., Wang, J. W., and Su, C.-Y. (2017). Electrophysiological recording from Drosophila trichoid sensilla in response to odorants of low wolatility. J. Visual. Exp. 125. doi: 10.3791/56147

Rudnev, V., Loveless, D., and Cook, R.L., (2017). Handbook of Induction Heating. Boca Raton, FL: CRC Press. 750. doi: 10.1201/9781315117485

Stanczyk, N. M., Brookfield, J. F. Y., Ignell, R., Logan, J. G., and Field, L. M. (2010). Behavioral insensitivity to DEET in Aedes aegypti is a genetically determined trait residing in changes in sensillum function. Proc. Natl. Acad. Sci. U.S.A. 107, 8575-8580. doi: 10.1073/pnas.10013 13107

Stelinski, L. L., Miller, J. R., Ressa, N. E., and Gut, L. J. (2003). Increased EAG responses of tortricid moths after prolonged exposure to plant volatiles: evidence for octopamine-mediated sensitization. J. Insect Physiol. 49, 845-856. doi: 10.1016/S0022-1910(03)00136-7

Syntech (2015). Electroantennography: A Practical Introduction Ockenfels Syntech $\mathrm{GmbH}$. Available online at: http://www.ockenfels-syntech.com/wp-content/ uploads/EAGpract_man_fin (accessed June 10, 2019).

Zwiebel, L. J., and Pask, G. M. (2016). Thermal Volatilization of Orco Agonist. Patent WO2017011466. Available online at: https://patents.google.com/patent/ WO2017011466A1/en (accessed June 19, 2019).

Conflict of Interest Statement: The authors declare that the research was conducted in the absence of any commercial or financial relationships that could be construed as a potential conflict of interest.

Copyright (c) 2019 Yang, Liu, Richoux, Bernier, Linthicum and Bloomquist. This is an open-access article distributed under the terms of the Creative Commons Attribution License (CC BY). The use, distribution or reproduction in other forums is permitted, provided the original author(s) and the copyright owner(s) are credited and that the original publication in this journal is cited, in accordance with accepted academic practice. No use, distribution or reproduction is permitted which does not comply with these terms. 